\title{
Self-Care Practices of Common Cold and Influenza among the Elderly in Alexandria, Egypt
}

\author{
Hala Kadry Ibrahim ${ }^{1}$, Heba Mahmoud Elkady ${ }^{2}$ \\ ${ }^{1}$ Public Health Nursing, Family Health Department, High Institute of Public Health, Alexandria University \\ ${ }^{2}$ Geriatric Health, Family Health Department, High Institute of Public Health, Alexandria University
}

\begin{abstract}
Background: Self-care is the most common and fundamental form of health care. Aim: The aim of this study was to explore the self-care practices of cold and influenza among the elders. Subjects and methods: A cross-sectional design was used over a period of three months (January-March 2014). Interviews were conducted with 192 elders recruited from all elderly clubs in Alexandria. Results: Hot / cold fluids intake and administration of medications were the most common categories of self-care practices (97.9\% and $89.1 \%$ respectively). The most commonly used medications were aspirin and analgesics (97.1\%), followed by antitussives (70.2\%) and antibiotics (48.5\%). Regarding seeking physician help, only one third of the elders (35.4\%) reported they would visit a physician. The most common criterion mentioned for seeking professional assistance was unusual patterns of symptoms (42.6\%) and increased severity of symptoms (39.8\%). The results also showed that the highest percentage of elders (63.0\%) used traditional medicine during their illness. While, only $7.8 \%$ of the elders obtained influenza vaccine. Conclusion: Elders were very active self-care agents, reporting both a large number and a variety of cold and influenza related self-care actions. Clearly, further research about general patterns and specific self-care actions taken by elderly in response to a variety of health deviations is needed.
\end{abstract}

Keywords: Self-care, common cold, influenza (flu), elderly.

\section{Introduction}

Upper respiratory infections or colds are inflammation of the upper respiratory tract caused by many different virus strains that cannot be cured by antibiotics. They have to be differentiated from influenza which is a very common respiratory illness. It usually occurs in $15-25 \%$ of the world's human population each year (Rush et al., 2006). This illness typically has a low death rate, with average overall mortality rates of $0.1 \%$ or less. However, influenza carries much higher rates of morbidity and mortality in the elderly and other vulnerable populations, and thus it is of special interest to geriatricians and public health physicians (Nahas et al., 2011). Influenza is much more likely to result in hospitalization and death in the elderly than in young persons. As many as 35,000 excess geriatric deaths due to pneumonia and influenza occur during influenza epidemics each year (Conn, 2001).

Older adults and people with chronic diseases are at the greatest risk of problems associated with seasonal flu. Of all age groups, individuals older than age 84 have the highest risk of dying from seasonal flu complications (Dean 1986). Most developed countries offer elderly people vaccination against predicted influenza strains for the next season. However, the age related decline of immune function reduces the ability of elderly patients to respond to the influenza vaccine, and the vaccine is less effective in patients with chronic diseases (Nahas et al., 2011). Surveys suggest that the main reasons for refusing the vaccination are fear of side effects, fear that vaccinations will cause influenza, dislike of injections, being unaware that the vaccination is useful or available, and lack of time or forgetfulness (Rush et al., 2006). The challenge to the health services is to overturn the misconceptions and provide an easy access service within which there are no reasons to refuse vaccination (Conn, 2001).
On average, individuals older than 60 have less than one cold a year. Only symptomatic treatment is available for uncomplicated cases of the common cold: bed rest, plenty of fluids, gargling with warm salt water, petroleum jelly for a raw nose, and aspirin or acetaminophen to relieve headache or fever (Nahas et al., 2011). There are many over-the-counter common cold medications that include decongestants, cough syrups, nasal drops and antihistamines (Lowe et al., 2009). The decision to seek medical care will be affected by factors such as age, existing health problems, having heart or lung disease, having a chronic condition that requires regular medical attention, being frail, or immunesupression (Figueiras et al., 2000).

Much of the time, home treatment and self care can relieve most symptoms and reduce the risk for further problems. Self care measures include taking basic pain/fever relievers and using a hot water bottle or heating pad (British Columbia Health Files, 2006). In elders, medical care should be sought right away if any of the following symptoms are present: difficulty breathing or shortness of breath, pain or pressure in the chest or stomach, confusion or disorientation, coughing up bloody sputum, severe vomiting or if symptoms improve and then suddenly become worse (Conn, 2001).

One definition of self-care is the performance by consumers of activities traditionally carried out by health care providers (Zapka and Barry, 2009). Although selfcare has its roots outside the traditional medical system, the concept is increasingly considered for integration within established health programs (Zapka and Estabrook, 2006). This trend needs to be carefully evaluated with respect to educational effectiveness, patient behavior variables, medical result, patient/provider acceptance, as well as cost benefit (Becker, 2007). 


\section{International Journal of Science and Research (IJSR) \\ ISSN (Online): 2319-7064 \\ Index Copernicus Value (2013): 6.14 | Impact Factor (2014): 5.611}

Self-care for illnesses is not a rare phenomenon but rather the norm. The extensive use of self-care is not surprising given the high annual incidence of the common cold with a rate of three visits for adolescents and adults (Vingilis et al., 2008). However, despite the extensive use of self-care there seems to be heavy use of medical resources for respiratory problems. It was reported that $12.6 \%$ of office visits to physicians were diagnosed as the common cold. Furthermore, the utilization patterns for the common cold indicated that outpatient clinics, emergency departments and after hours services were used five times as often as regular office visits (Estabrook, 2009).

Moreover, self-medication (SM), defined as the use of any drug not prescribed by a licensed health practitioner, or any alteration to the recommended dose guidelines undertaken by the patient (World Health Organization, 1986; Abdelwahid, 1998), can be understood as a modern style of self-care which is becoming increasingly important in developed countries. Factors such as a decrease in prescription coverage, an increase in the use of alternative remedies, availability of over-the-counter health products, and an increasing presence of pharmaceutical products in the media, are probably among the causes of the rise of SM (Sexton and McClain, 2011).

\section{Materials and Methods}

Subjects included 192 elders aged 60 years and over of both sexes. Elders were recruited from all (6) elderly clubs in Alexandria. A cross-sectional design was used. Each club was visited for a period of one month, all elders who had no verbal or mental problems and who accepted to participate in the study were interviewed. The purpose of the study was explained and elders were assured for confidentiality. The average number of non-repeated names of elderly who attended each club was around $30 /$ month. Elders who consistently received help from a caregiver or whose health care decisions were consistently made by others were not included in the sample. The interviews were completed in the elderly clubs and each lasted from 25 to 50 minutes. The data were collected by the researchers and extended over a period of three months from the beginning of Janaury 2014 till the end of March 2014. Each elderly club was visited once per week. Informed consents were obtained from the participants for their inclusion in the study.

A structured interview questionnaire was developed by the researchers. A panel of five experienced staff members (Faculty of Nursing and High Institute of Public Health) judged the questionnaire. The questionnaire was pilot-tested with 18 respondents ( $10 \%$ of the sample size). Results of this pretest were further incorporated into the questionnaire. The questionnaire was used to collect information about: sociodemographic characteristics such as name, age, sex, marital status, level of education, income, and living arrangements. Also, the questions were primarily closed-ended: and included five items about some reported practices of the elders regarding the protective measures against cold / influenza, signs and symptoms, self management practices, reported medications for cold / influenza symptoms relief and seeking medical care (consulting a doctor). An open ended question was included in case of using traditional medicine (simple recipe) for symptom relief and was classified into categories. Cronbach Alpha coefficient was used to ascertain the reliability of the tool $(\mathrm{r}=0.73)$.

The study was approved by the ethics committee in the High Institute of Public Health (HIPH) - Alexandria University on the basis of the Declaration of Helsinki.

\section{Conflict of Interest}

The authors declare that they have no conflict of interest.

\section{Statistical Analysis}

After data were collected, they were coded then introduced into the computer. All the results were tabulated and analyzed using Statistical Package for the Social Sciences, SPSS version 16.0 (SPSS Inc., Chicago, Illinois, USA) and Microsoft Excel 2007. The following statistical measures were performed: data were summarized using descriptive statistics: mean, SD, range values for quantitative variables and number and percentage for qualitative values. Statistical differences between groups were tested using the $\mathrm{X}^{2}$ - test for qualitative variables. A p-value less than or equal to 0.05 was considered to be statistically significant.

\section{Results}

Regarding socio-demographic characteristics of the study sample, the present study revealed that about two thirds of elders were females (64.6\%). Elders' ages ranged from 60 to 83 years (mean $\pm \mathrm{SD}=67.5 \pm 5.05$ ). It also showed that about half of the elders (50.5\%) were married and $44.8 \%$ were widowed or divorced. In addition, about one third of the elders (35.4\%) completed their secondary education, $19.8 \%$ were university graduates and only $17.7 \%$ were illiterate or could only read and write. The table also showed that the income of $34.4 \%$ of elders was 1000 to less than 2000 pounds/month and only $12.5 \%$ less than 500 pounds. As regards the living arrangement, more than two thirds of elders lived in a family setting (68.8\%). It was reported that the most common symptoms of cold / flu recognized by those elders were runny nose or nasal congestion (80.7\%), fatigue (60.9\%), throat irritation or pain (56.2\%), headache (54.2\%) and sneezing (52.1\%).

Figure 1 showed that the highest percentage of elders reported dressing heavily as the most commonly taken preventive action (90.6\%), followed by avoiding persons with colds (78.1\%) and having adequate nutrition and fluids (70.3\%). On the other hand, only $7.8 \%$ of the elders obtained influenza vaccine.

As regards self-care practices for managing cold / flu, table 1 shows that increase hot / cold fluids intake and administration of medications were the most commonly reported of self-care practices (97.9\%, 89.1\% respectively). Regarding types of medication consumed, the table showed that $97.1 \%$ of the medications used were aspirin and analgesics, followed by antitussives (70.2\%) and antibiotics (48.5\%).

\section{Volume 5 Issue 3, March 2016




\section{International Journal of Science and Research (IJSR) \\ ISSN (Online): 2319-7064}

Index Copernicus Value (2013): 6.14 | Impact Factor (2014): 5.611

As regards seeking physician help, only one third of the elders (35.4\%) reported they would visit a physician. The most common reason (42.6\%) mentioned for seeking professional assistance was unusual patterns of symptoms (longer duration, or no response to usual self-care actions) and increased severity of symptoms (39.8\%).

Table 2 showed that about one third of elders did not use traditional medicine during their illness. It also showed that the highest percentage of elders (31.8\%) used to drink cold citrus or hot herbal fluids (18.2\%) or hot lemon juice $8.3 \%$ and only $2.6 \%$ used combinations of honey/ lemon/ olive oil/ molasses. Also, the results revealed that about one quarter of elders (27.6\%) reported drinking chicken soup and $4.2 \%$ of them used raw garlic.

Table 3 showed that there was a significant difference in traditional medicine intake regarding marital status with the highest intake recorded among married (73.2\%) and the lowest among widowed or divorced elders (52.3\%).

Income was a significant predictor for drug intake, where the highest (95.8\%) drug intake was reported among elders whose income was $<500$ L.E per month.

It can also be observed that there was a significant difference in vit C intake among elders whose income was 2000 L.E and above per month. Also, the results indicated that there was a significant difference in vit c intake regarding living arrangements with the highest intake recorded among elders who lived alone (65.9\%).

As regards seeking physician help, living arrangements was a significant predictor, where the highest percentage of elders who sought physician help were those who lived with their family (81.1\%).

The studied relations with other socio-demographic variables (age, sex and education) showed no significant differences at any behavior.

Table 4 showed that there was a significant difference in dressing warmly regarding age with the highest percentage reported among age group 70 and above years old ( $\mathrm{p}=$ 0.050). It can also be observed that there was a significant difference in good nutrition and fluids intake among younger elderly (60 to less than 65 years old) $(p=0.034)$. Education was a significant predicator for dressing heavily, avoiding persons during illness and washing hands regularly with the highest percentage recorded among university and above of education ( $\mathrm{p} \leq \mathrm{0.05})$. Income was a significant predictor for dressing heavily, where the highest percentage of elders who dressed heavily (100\%) were among those whose income was 2000 and above L.E per month $(p=0.000)$. There was a significant difference in dressing heavily in relation to living arrangements with the highest percentage (96.7\%) reported among elders who lived alone $(p=0.053)$. The studied relations with other socio-demographic variables showed no significant differences in any preventive actions.

\section{Discussions}

The common cold is the most common acute illness that affects mankind. Rates of severe illness and death are highest in patients aged $\geq 65$ years, compared to younger patients, and accurate diagnosis will influence treatment options (Coetzer, 2012). The common cold is the most usual reason for a visit to general practitioner or pharmacy, and elderly patients may often present to the pharmacy requiring over-the-counter (OTC) treatment for these symptoms. Elderly patients have a three to seven times greater incidence of adverse drug reactions compared to the younger population, and treating these patients can be challenging (Figueiras et al., 2000).

Influenza causes substantial mortality and morbidity in elderly people, particularly those with chronic diseases. Influenza vaccine is the only reported strategy for influenza prevention. Other influenza prevention strategies have not been commonly reported (Jordan and Hawker, 2006).

An annual influenza vaccination remains the best protection from influenza, and is recommended for all patients over the age of 65 years. The present study revealed that the highest percentage of elders reported dressing heavily as the most commonly taken preventive action (90.6\%), followed by avoiding persons with colds (78.1\%) and having adequate nutrition and fluids (70.3\%). On the other hand, only $7.8 \%$ of the elders got vaccinated against influenza. This goes with another study carried out on a group of community dwelling elders in the USA which revealed that the subjects selected the following preventive strategies: stayed at home (74\%), drank fluids (68\%), dressed heavily $80 \%$ and only $20 \%$ got vaccinated (Millong, 2012). Perception that one is healthy and thus does not need the vaccine, or that one is too ill to receive the vaccine may be the cause of underutilization. Other factors may be concerns about the side effects, lack of confidence in the efficacy of the vaccine, fear of injections adverse side effects from previous vaccinations.

The present work showed that several significant predictors were reported regarding dressing heavily namely age, education, income and living arrangements where the highest percentage of elders who dressed heavily were among the age group 70 and above years old $(\mathrm{p}=0.050)$, among elders whose income was 2000 pounds and above per month $(\mathrm{p}=0.000)$ and among elders who lived alone ( $p=0.053)$. It can also be observed that there was a significant difference in good nutrition and fluids intake among younger elderly (60 to less than 65 years old $)(p=0.034)$. Education was also a significant predicator for avoiding persons during illness and washing hands regularly with the highest percentage recorded among university graduates and those who had postgraduate degrees $(\mathrm{p} \leq \mathrm{0.05})$.

This is in accordance with other studies (Figueiras et al., 2000; The Centers for Disease Control and Prevention, 2012) which revealed that the highest prevalence of preventive actions in general against a cold or flu attacks were found among women, people who lived alone, and 


\section{International Journal of Science and Research (IJSR) \\ ISSN (Online): 2319-7064 \\ Index Copernicus Value (2013): 6.14 | Impact Factor (2014): 5.611}

those who finished their secondary education. This may represent a higher tendency towards self-care among women, and among the highly educated who probably have greater knowledge, greater economic power, less confidence in the doctor, and a greater feeling of personal autonomy.

Several studies (Abdelwahid, 1998; Sexton et al., 2011) revealed that older subjects were the least to take preventive actions. This may be due to the fact that among a high percentage of elders, medicines are freely prescribed and thus they may feel unworried about catching a cold or influenza. It may also be related to having more free time to visit the doctor, thus they feel that catching a cold may not be such an important issue.

Because no cure currently exists, treatment goals should include reducing symptoms, improving daily functioning, and preventing the spread of disease to others (World Health Organization, 1986). The present study revealed that increased hot / cold fluids intake and administration of medications were the most commonly reported of self-care practices $(97.9 \%, 89.1 \%$ respectively).This is in agreement with another study carried out in Spain (Ashley and Stefanie, 2009) which revealed that non-pharmacologic measures including adequate rest, increased fluid intake, and nutritious meal or snack selections, inexpensive foods such as tea with lemon and honey, chicken soup, and broths were the most commonly used measures among the elders in the study sample.

Treating the elderly for cold and influenza symptoms can be challenging, and rational drug use is even more important in the elderly than in other age groups because of the presence of concomitant medical conditions and concurrent drug therapy (Coetzer, 2012). Regarding types of medication consumed, the present study showed that $89.1 \%$ of elders used drugs to treat their cold and influenza and that $97.1 \%$ of the medications used were aspirin and analgesics, followed by antitussives (70.2\%) and antibiotics (48.5\%). This goes with another study which revealed that $79 \%$ of elders used medications (Conn, 2001) and another study which showed that elders experienced symptom improvement when utilizing humidifiers or vaporizers and nasal decongestants.

The present work revealed that seeking physician help was reported among only one third of the elders (35.4\%). The most common reason (42.6\%) mentioned for seeking professional assistance was unusual patterns of symptoms (longer duration, or no response to usual self-care actions) and increased severity of symptoms (39.8\%). This is in accordance with other studies (Conn, 2001; Sexton et al., 2011) which revealed that only $29 \%$ of elders paid a visit to their physician when having a common cold and may be attributed to cultural, economic or educational factors.

The present study also revealed that living arrangements was a significant predictor for physician visits, where the highest percentage of elders who sought physician help were those who lived with their family (81.1\%). It also revealed that income was a significant predictor for drug intake, where the highest (95.8\%) drug intake was reported among elders whose income was $<500$ L.E per month. This is in agreement with another study (Vingilis et al., 2008 ) which showed that physician visits was more reported among the elderly who had more children in the household. However, Warren 1994, analyzing the Ontario Health Survey found that low-income, elders reported more visits to a general practitioner.

The present work also showed that there was a significant difference in traditional medicine intake regarding marital status with the highest intake recorded among married (73.2\%) and the lowest among widowed or divorced elders (52.3\%). Also, the results indicated that there was a significant difference in vitamin $\mathrm{C}$ intake regarding living arrangements with the highest intake recorded among elders who lived alone (65.9\%). It can also be observed that there was a significant difference in vitamin $C$ intake among elders whose income was 2000 L.E and above per month. This goes with other studies which reported a higher prevalence of traditional medicine and vitamin $\mathrm{C}$ intake among persons living alone (Figuerias et al., 2000; British Columbia Health Files, 2006), but differs from other studies which relate the intake to medicines stored at home as a consequence of prescriptions given to other members of the family (Becker, 2007; Jordan et al., 2006). Greater prevalence in this group may be also due to a more pronounced feeling of independence resulting in a lower tendency to visit the doctor.

The studied relations with other socio-demographic variables (age, sex and education) in the present work showed no significant differences in any behavior. This differs from other studies (Figueiras et al., 2000; British Columbia Health Files, 2006) which reported female sex, higher age and higher level of education as indicators for higher traditional medicine use where greater knowledge of traditional medicine and higher experience with old age were found to lead to a greater feeling of personal autonomy and greater incidence of self-medication among persons with higher educational levels. These older adults were very active self-care agents, reporting both a large number and a variety of cold and influenza related selfcare actions. Clearly, further research about general patterns and specific self-care actions used by elderly in response to a variety of health deviations is needed.

It is probable that the impact of respiratory infections in the elders will be more extensively documented. Understanding of the immunology and pathogenesis of respiratory infections in elderly adults is of paramount importance, and considerable work will need to be performed towards development of effective prevention and control measures (Treanor and Falsey, 2009).

In addition, this study may give health educators, planners and other health professionals' information that will help reduce undesirable self medication and promote positive and responsible self-care actions during illness.

\section{Acknowledgments}

The authors thank all elderly who participated in the study and also, they express their appreciation to the directors of all clubs for facilitating the work. 


\section{International Journal of Science and Research (IJSR) \\ ISSN (Online): 2319-7064 \\ Index Copernicus Value (2013): 6.14 | Impact Factor (2014): 5.611}

\section{References}

[1] Abdelwahid A (1998). Self-medication among primary care patient in Farazdak clinic in Riyadh. Soc Sci Med 27: 287-289

[2] Ashley B, Stefanie F (2009) MTM Session: Targeting the common cold. Homepage on the Internet. http://www.pharmacytimes.com/ Accessed 17 December 2015

[3] Becker M (2007). Selected psychosocial models and correlates of individual health-related behaviors. Medical Care 15:27-33

[4] British Columbia Health Files (2006). Self-care during an influenza pandemic. Pandemic Influenza Series 250(94): 62-69

[5] Centers for Disease Control and Prevention (2012). Impact of influenza vaccination on seasonal mortality in the US elderly population. Homepage on the Internet. http://www.niaid.nih.gov/news/newsreleases/2005/pages /simonsen.aspx Accessed 19 December 2015

[6] Coetzer R (2012). Colds and flu medication in the elderly. S Afr Pharm J 79(5):35-37

[7] Conn V (2001). Self-care actions taken by older adults for influenza and cold. Nursing Research 40(3):176-181

[8] Dean K (1986). Self-care behaviors: Implications for aging. In: Dean K, Hickey T, Holestein B (eds) Self-care and health in old age. Dover, Croom Helm, pp.58-93

[9] Estabrook B (2009). Consumer impact of a cold selfcare center in a prepaid ambulatory care setting. Medical Care 4(18):123-128

[10] Figueiras A, Caamano F, Jesu A, Gestal-Otero J (2000). Socio-demographic factors related to self-medication in Spain. European Journal of Epidemiology 16: 19-26

[11] Jordan R, Hawker JI (2006). Influenza in elderly people in care homes: New evidence strengthens policy to vaccinate healthcare workers. BMJ 333:1229-1230

[12] Lowe NK, Ryan-Wenger N M (2009). Over the counter medications and self-care. The Nurse Practitioner.; 24(12): 34-44.
[13] Millong MK (2012). Helping patients manage cough, cold and flu. Retail Clinician. Homepage on the Internet.

http://www.4healtheducation.com/pdf/WinterRetailCl inicianCE-CoughColdFlu-fulllessonforonlineFINAL.pdf. Accessed 12 December 2015

[14] Nahas R, Balla A (2011). Complementary and alternative medicine for prevention and treatment of common cold. Can Fam Physician 57:31-36

[15] Rush P, Steven L (2006). Influenza in the elderly. Clinical Journal of the American Geriatric Society 14(2): 9-14

[16] Sexton D, McClain M (2011). The common cold in adults: Diagnosis and clinical features. UpTo-Date. Homepage on the Internet. http://www.uptodate.com/contents/the-common-coldin-adults-diagnosis-and-clinical-features. Accessed 7 November 2015

[17] Treanor J, Falsey A (1999). Review respiratory viral infections in the elderly. Antiviral Research 44(9):79-102

[18] World Health Organization (1986). Guidelines for the medical assessment of drugs for use in selfmedication. Copenhagen: WHO, Regional Office for Europe.

[19] Warren R (1994). Ontario health communities coalition. Journal of Rural Community 6(2): 21-43

[20] Vingilis E, Brown U, Koeppen R, Hennen B, Bass M, Peyton K, et al (2008). Evaluation of a cold/flu selfcare public education campaign. Health Education Research. Theory \& Practice 13(l): 33-46

[21] Zapka J, Barry W (2009). Self-care for colds: A costeffective alternative to upper respiratory infection management. Am J Public Health 69: 814-816

[22]Zapka J, Estabrook B (2006). Medical self-care programs. Health Care Management Review 1:75-81

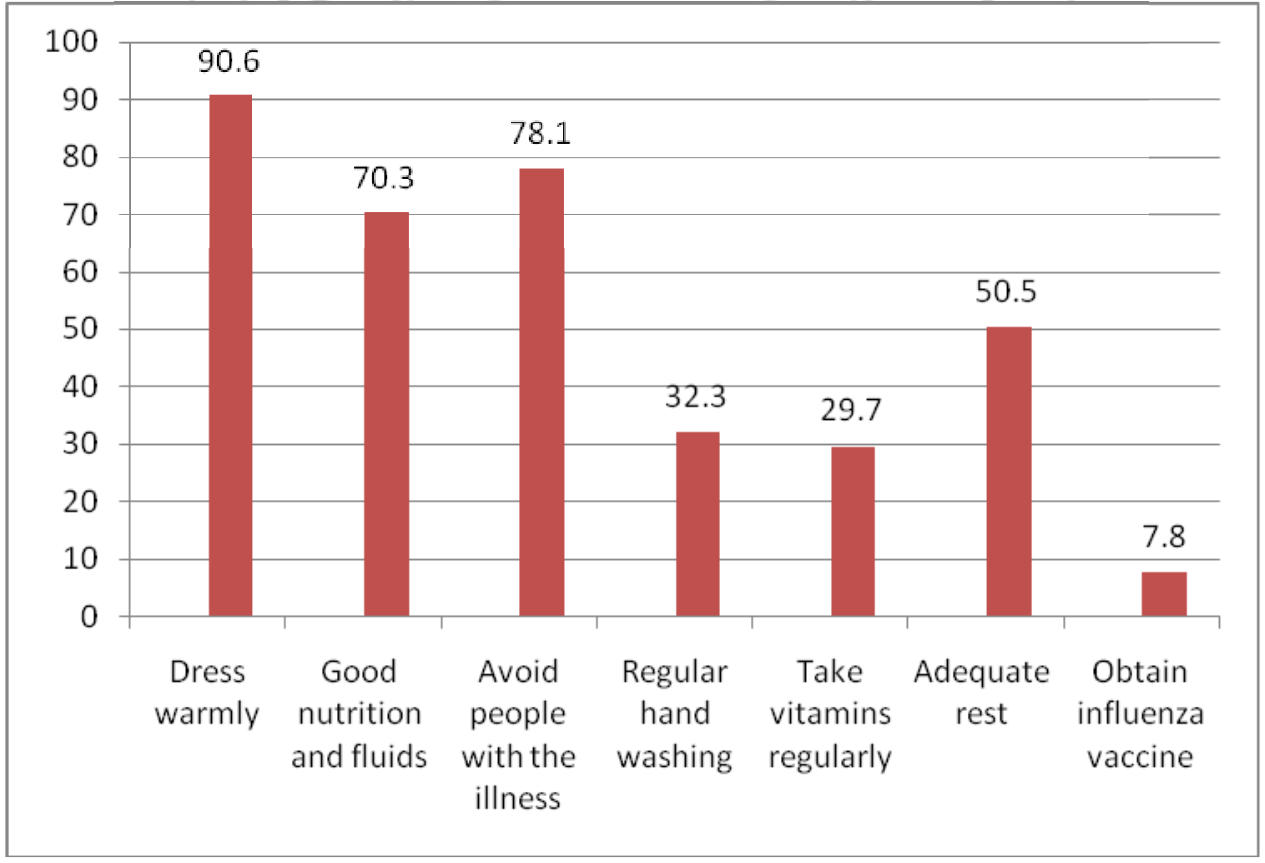

Figure 1: Cold / flu prevention actions 


\section{International Journal of Science and Research (IJSR) ISSN (Online): 2319-7064}

Index Copernicus Value (2013): 6.14 | Impact Factor (2014): 5.611

Table 1: Self-care practices during illness Alexandria, 2014

\begin{tabular}{|l|c|}
\hline Self-care practices & $\begin{array}{c}\text { No. (\%) } \\
\mathbf{n}=\mathbf{1 9 2}\end{array}$ \\
\hline Administer medications & $171(89.1 \%)$ \\
\hline Reported medications for cold / flu (n=171) & \\
\hline Aspirin and analgesics & $166(97.1 \%)$ \\
\hline Antihistamines & $55(32.2 \%)$ \\
\hline Antitussives & $120(70.2 \%)$ \\
\hline Antibiotics & $83(48.5 \%)$ \\
\hline Vitamin C & $72(42.1 \%)$ \\
\hline Increase hot / cold fluids intake & $187(97.9 \%)$ \\
\hline Adequate rest & $104(54.2 \%)$ \\
\hline Light food intake & $67(34.9 \%)$ \\
\hline Seeking physician help & $68(35.4 \%)$ \\
\hline Reasons for seeking physician help (n=68) & \\
\hline Severity of symptoms & $27(39.8 \%)$ \\
\hline Unusual patterns of symptoms & $29(42.6 \%)$ \\
\hline Fear of potential hazards & $12(17.6 \%)$ \\
\hline
\end{tabular}

Table 2: Traditional medicine used during illness Alexandria, 2014

\begin{tabular}{|c|c|}
\hline Items & $\begin{array}{c}\text { No. (\%) } \\
\mathbf{n = 1 9 2}\end{array}$ \\
\hline None & $71(37.0 \%)$ \\
\hline Cold citrus fluids (lemon and orange) & $61(31.8 \%)$ \\
\hline $\begin{array}{c}\text { Hot herbal fluids (guava leaves, anise, tilia, ginger } \\
\text { with cinnamon, combination, soup, leban dakar }\end{array}$ & $35(18.2 \%)$ \\
\hline Hot lemon juice & $16(8.3 \%)$ \\
\hline Chicken soup & $53(27.6 \%)$ \\
\hline Raw garlic intake & $21(4.2 \%)$ \\
\hline Combination of honey/ lemon/ olive oil/molasses & $5(2.6 \%)$ \\
\hline
\end{tabular}

Table 3: Relation between actions taken during the illness and some socio-demographic variables Alexandria, 2014

\begin{tabular}{|c|c|c|c|c|c|c|c|c|c|}
\hline \multirow{2}{*}{\multicolumn{2}{|c|}{ Socio-demographic variables }} & \multicolumn{2}{|c|}{$\begin{array}{c}\text { Seeking } \\
\text { physician help }\end{array}$} & \multicolumn{2}{|c|}{ Drug intake } & \multicolumn{2}{|c|}{$\begin{array}{c}\text { Traditional } \\
\text { medicine }\end{array}$} & \multicolumn{2}{|c|}{ Vit $C$ intake } \\
\hline & & No. & $\%$ & No. & $\%$ & No. & $\%$ & No. & $\%$ \\
\hline \multirow{3}{*}{ Age (years) } & $60-$ & 50 & $84.7 \%$ & 52 & $88.1 \%$ & 33 & $55.9 \%$ & 18 & $30.5 \%$ \\
\hline & $65-$ & 59 & $79.7 \%$ & 68 & $91.9 \%$ & 52 & $70.3 \%$ & 29 & $39.2 \%$ \\
\hline & $70+$ & 42 & $71.2 \%$ & 51 & $86.4 \%$ & 36 & $61.0 \%$ & 25 & $42.4 \%$ \\
\hline \multicolumn{2}{|r|}{$\mathrm{P}$} & \multicolumn{2}{|c|}{0.191} & \multicolumn{2}{|c|}{0.584} & \multicolumn{2}{|c|}{0.218} & \multicolumn{2}{|c|}{0.383} \\
\hline \multirow{2}{*}{ Sex } & Male & 54 & $79.4 \%$ & 59 & $86.8 \%$ & 41 & $60.3 \%$ & 26 & $38.2 \%$ \\
\hline & Female & 97 & $78.2 \%$ & 112 & $90.3 \%$ & 80 & $64.5 \%$ & 46 & $37.1 \%$ \\
\hline \multicolumn{2}{|r|}{$\mathrm{P}$} & \multicolumn{2}{|c|}{0.848} & \multicolumn{2}{|c|}{0.450} & \multicolumn{2}{|c|}{0.562} & \multicolumn{2}{|c|}{0.876} \\
\hline \multirow{3}{*}{ Marital status } & Married & 80 & $82.5 \%$ & 87 & $89.7 \%$ & 71 & $73.2 \%$ & 36 & $37.1 \%$ \\
\hline & Widowed or divorced & 63 & $73.3 \%$ & 75 & $87.2 \%$ & 45 & $52.3 \%$ & 34 & $39.5 \%$ \\
\hline & Single & 8 & $88.9 \%$ & 9 & $100.0 \%$ & 5 & $55.6 \%$ & 2 & $22.2 \%$ \\
\hline \multicolumn{2}{|r|}{$\mathrm{P}$} & \multicolumn{2}{|c|}{0.235} & \multicolumn{2}{|c|}{0.485} & \multicolumn{2}{|c|}{$0.013^{*}$} & \multicolumn{2}{|c|}{0.590} \\
\hline \multirow{4}{*}{ Educational level } & Illiterate or read and write & 29 & $82.3 \%$ & 31 & $45.6 \%$ & 21 & $41.2 \%$ & 10 & $23.9 \%$ \\
\hline & Primary or preparatory & 37 & $71.2 \%$ & 45 & $86.5 \%$ & 36 & $69.2 \%$ & 24 & $46.2 \%$ \\
\hline & Secondary & 54 & $79.4 \%$ & 60 & $88.2 \%$ & 39 & $57.4 \%$ & 29 & $42.6 \%$ \\
\hline & University and above & 31 & $81.6 \%$ & 35 & $92.1 \%$ & 25 & $65.8 \%$ & 9 & $23.7 \%$ \\
\hline \multicolumn{2}{|r|}{$\mathrm{P}$} & \multicolumn{2}{|c|}{0.455} & \multicolumn{2}{|c|}{0.819} & \multicolumn{2}{|c|}{0.662} & \multicolumn{2}{|c|}{0.208} \\
\hline \multirow{5}{*}{ Income/month } & $<500$ & 21 & $87.5 \%$ & 23 & $95.8 \%$ & 14 & $58.3 \%$ & 6 & $25.0 \%$ \\
\hline & $500-<800$ & 28 & $84.8 \%$ & 31 & $93.9 \%$ & 19 & $57.6 \%$ & 13 & $39.4 \%$ \\
\hline & $800-<1000$ & 45 & $78.9 \%$ & 53 & $93.0 \%$ & 34 & $59.6 \%$ & 15 & $26.3 \%$ \\
\hline & $1000-<2000$ & 49 & $74.2 \%$ & 56 & $84.8 \%$ & 45 & $68.2 \%$ & 29 & $43.9 \%$ \\
\hline & $2000+$ & 8 & $66.7 \%$ & 8 & $66.7 \%$ & 9 & $75.0 \%$ & 9 & $75.0 \%$ \\
\hline \multicolumn{2}{|r|}{$\mathrm{P}$} & & 453 & & $37 *$ & & & & $04 *$ \\
\hline & Alone & 44 & 51.6 & 54 & $70.1 \%$ & 31 & $47.8 \%$ & 25 & $65.9 \%$ \\
\hline Living arrangements & With family & 107 & $81.1 \%$ & 117 & $88.6 \%$ & 90 & $68.2 \%$ & 47 & $35.6 \%$ \\
\hline & $\mathrm{P}$ & & $02 *$ & & 142 & & 89 & & $07 *$ \\
\hline
\end{tabular}

Pearson Chi-Square Tests

* Significant at $\mathrm{p} \leq 0.05$ 


\section{International Journal of Science and Research (IJSR) \\ ISSN (Online): 2319-7064 \\ Index Copernicus Value (2013): 6.14 | Impact Factor (2014): 5.611}

Table 4: Relation between actions taken to prevent illness and some socio-demographic variables Alexandria, 2014

\begin{tabular}{|c|c|c|c|c|c|c|c|c|c|c|c|c|c|c|c|}
\hline \multirow{2}{*}{\multicolumn{2}{|c|}{$\begin{array}{c}\text { Socio-demographic } \\
\text { Variables }\end{array}$}} & \multicolumn{2}{|c|}{$\begin{array}{c}\text { Dress } \\
\text { warmly } \\
\mathrm{n}=174\end{array}$} & \multicolumn{2}{|c|}{$\begin{array}{c}\text { Good } \\
\text { nutrition } \\
\text { \& fluids } \\
\mathrm{n}=135\end{array}$} & \multicolumn{2}{|c|}{$\begin{array}{l}\text { Take } \\
\text { vitamins } \\
\text { regularly } \\
\mathrm{n}=57\end{array}$} & \multicolumn{2}{|c|}{$\begin{array}{c}\text { Avoid } \\
\text { persons } \\
\text { during } \\
\text { illness } \\
\mathrm{n}=150\end{array}$} & \multicolumn{2}{|c|}{$\begin{array}{c}\text { Adequate } \\
\text { rest } \\
\mathrm{n}=97\end{array}$} & \multicolumn{2}{|c|}{$\begin{array}{c}\text { Wash hand } \\
\text { regularly } \\
n=62\end{array}$} & \multicolumn{2}{|c|}{$\begin{array}{c}\text { Obtain } \\
\text { influenza } \\
\text { vaccine } \\
\mathrm{n}=15\end{array}$} \\
\hline & & No. & $\%$ & No. & $\%$ & No. & $\%$ & No. & $\%$ & No. & $\%$ & No. & $\%$ & No. & $\%$ \\
\hline \multirow{3}{*}{ Age (years) } & $60-$ & 51 & 86.4 & 46 & 78.0 & 18 & 30.5 & 45 & 76.3 & 27 & 45.8 & 25 & 42.4 & 3 & 5.1 \\
\hline & $65-$ & 65 & 87.8 & 55 & 74.3 & 23 & 31.1 & 60 & 81.1 & 38 & 51.4 & 24 & 32.4 & 6 & 8.1 \\
\hline & $70+$ & 58 & 98.3 & 34 & 57.6 & 16 & 27.1 & 45 & 76.3 & 32 & 54.2 & 13 & 22.0 & 5 & 8.5 \\
\hline \multicolumn{2}{|r|}{$\mathrm{P}$} & \multicolumn{2}{|c|}{$0.050 *$} & \multicolumn{2}{|c|}{$0.034 *$} & \multicolumn{2}{|c|}{0.872} & \multicolumn{2}{|c|}{0.735} & \multicolumn{2}{|c|}{0.484} & \multicolumn{2}{|c|}{0.061} & \multicolumn{2}{|c|}{0.826} \\
\hline \multirow{2}{*}{ Sex } & Male & 63 & 92.6 & 48 & 70.6 & 19 & 27.9 & 56 & 82.4 & 39 & 57.4 & 20 & 29.4 & 4 & 5.9 \\
\hline & Female & 111 & 89.5 & 87 & 70.2 & 38 & 30.6 & 94 & 75.8 & 58 & 46.8 & 42 & 33.9 & 10 & 8.1 \\
\hline \multicolumn{2}{|r|}{$\mathrm{P}$} & \multicolumn{2}{|c|}{0.477} & \multicolumn{2}{|c|}{0.951} & \multicolumn{2}{|c|}{0.695} & \multicolumn{2}{|c|}{0.294} & \multicolumn{2}{|c|}{0.161} & \multicolumn{2}{|c|}{0.527} & \multicolumn{2}{|c|}{0.774 (FEP) } \\
\hline \multirow{3}{*}{$\begin{array}{l}\text { Marital } \\
\text { status }\end{array}$} & Married & 89 & 91.8 & 63 & 64.9 & 23 & 23.7 & 78 & 80.4 & 52 & 3.6 & 36 & 37.1 & 6 & 6.2 \\
\hline & Widowed or div & 76 & 88.4 & 65 & 75.6 & 30 & 34.9 & 65 & 75.6 & 41 & 47.7 & 24 & 27.9 & 8 & 9.3 \\
\hline & Single & 9 & 100.0 & 7 & 77.8 & 4 & 44.4 & 7 & 77.8 & 4 & 44.4 & 2 & 22.2 & 0 & 0.0 \\
\hline \multicolumn{2}{|r|}{$P$} & 0.4 & 452 & & 257 & & & & 32 & & 15 & & 332 & & \\
\hline & $\begin{array}{c}\text { Illiterate or read and } \\
\text { write }\end{array}$ & 20 & 60.6 & 24 & 70.6 & 5 & 15.2 & 16 & 47.1 & 15 & 44.1 & 6 & 17.6 & 0 & 0.00 \\
\hline E & Primary or preparatory & 46 & 86.5 & 42 & 80.8 & 15 & 28.8 & 42 & 80.8 & 31 & 59.6 & 13 & 25.0 & 3 & 5.8 \\
\hline & Secondary & 67 & 97.1 & 45 & 66.2 & 20 & 29.0 & 58 & 84.1 & 36 & 52.9 & 27 & 39.7 & 5 & 7.4 \\
\hline & University and above & 38 & 100 & 24 & 63.2 & 17 & 44.7 & 34 & 89.5 & 15 & 39.5 & 16 & 42.1 & 6 & 15.8 \\
\hline & $\mathrm{P}$ & $\begin{array}{l}0.0 \\
(\mathrm{FI}\end{array}$ & $\begin{array}{l}00^{*} \\
\mathrm{EP})\end{array}$ & & 239 & & 58 & & $00 *$ & & 32 & $\overrightarrow{0.04}$ & *(FEP) & & \\
\hline & $<500$ & 17 & 70.8 & 18 & 75.0 & 8 & 33.3 & 20 & 80.3 & 10 & 41.7 & 5 & 20.8 & 0 & 0.0 \\
\hline & $500-<800$ & 26 & 78.8 & 19 & 57.6 & 13 & 39.4 & 27 & 81.8 & 17 & 51.5 & 10 & 30.3 & 1 & 3.0 \\
\hline In & $800-<1000$ & 55 & 96.5 & 40 & 70.2 & 13 & 22.8 & 42 & 73.7 & 30 & 52.6 & 23 & 40.4 & 4 & 7.0 \\
\hline & $1000-<2000$ & 65 & 97.0 & 47 & 71.2 & 17 & 25.8 & 50 & 75.8 & 31 & 47.0 & 19 & 28.8 & 8 & 12.1 \\
\hline & $2000+$ & 12 & 100.0 & 11 & 91.7 & 6 & 50.0 & 11 & 91.7 & 9 & 75.0 & 5 & 41.7 & 1 & 8.3 \\
\hline & $\mathrm{p}$ & $\begin{array}{l}0.0 \\
(\mathrm{FI} \\
\end{array}$ & $\begin{array}{l}00^{*} \\
\mathrm{EP})\end{array}$ & & 243 & & 15 & & 91 & & & & $\begin{array}{ll}00 \\
\mathrm{EP})\end{array}$ & & \\
\hline Living & Alone & 58 & 96.7 & 46 & 76.7 & 22 & 36.7 & 46 & 76.7 & 29 & 48.3 & 18 & 30.0 & 5 & 8.3 \\
\hline & With family & 116 & 87.9 & 89 & 67.4 & 35 & 26.5 & 104 & 78.8 & 68 & 51.5 & 44 & 33.3 & 9 & 6.8 \\
\hline & $P$ & 0.0 & $53 *$ & & 194 & & & & 42 & & 83 & & 547 & & \\
\hline
\end{tabular}

Pearson Chi-Square Tests

* Significant at $\mathrm{p} \leq 0.05$

\section{Author Profile}

Dr. Hala Kadry Ibrahim is Assistant Professor of Public Health Nursing, Family Health Department, High Institute of Public Health, Alexandria University, 165 El Horreya Avenue, El Hadara, Alexandria, Egypt. 